\title{
Gündelik Ahlaka Kuramsal Bakışlar: “Durun Ben Size Bir Hikaye Anlatayım"
} Theoretical Views on Everyday Morality: "Let Me Tell You a Story"

\section{Öz}

Bu yazıda ahlak psikolojisinin gündelik hayatın ahlakını anlama çabalarındaki gerek kuramsal gerek yöntemsel bazı eksikliklerine değinilecek ve olası bazı yöntemlerden bahsedilecektir. Ahlak kuramları, gerek tümdengelimci yaklaşımları gerekse de hipotetik ikilemler, özellikle de sıradışı hipotetik ikilemler gibi gündelik hayata uzak yöntemlerin kullanılması gibi sebeplerle gündelik ahlakın anlaşılmasında yeterince başarılı olamamıştır. Bağlam, kültür veya dil gibi ahlakın nasıl yapılandırıldığını, anlamlandırıldığını veya aktarıldığını etkileyen önemli yapılar, geleneksel ahlak çalışmalarında pek az yer tutmuştur. Antropolojik ahlak kuramlarının sağladığı açılımla kültürün etkisini de hesaba katmak durumunda kalan güncel ahlak kuramları, halen sıradan insanın ahlakı nasıl kavramsallaştırdığına yeterince eğilmemiştir. Doğal kavramsallaştırmalar incelendiğinde, gündelik hayatta ahlak meselesinin genel bazı ilkeler üzerinden değil bireysel özellikler ile ele alındığına dair bulgular mevcuttur. Gündelik ahlakı anlamanın belki en doğru yaklaşımlarından biri bu doğal kavramsallaştırmaları incelemektir.

\begin{abstract}
This paper discusses some theoretical and methodological deficiencies in morality psychology in understanding everyday morality and some possible methods to overcome. Morality theories using both the deductive approach and hypothetical dilemmas, especially thoe that are distant to ordinary life, have failed to understand everyday morality. Important structures such as context, culture, or language which affect how morality is constructed, given meaning, or transferred have had a very limited place in traditional morality theories. With the support of anthropological theories, contemporary theories which have had to consider cultural effects, still have not looked closely enough into natural morality conceptionalizations of the layperson. When these natural conceptualizations were investigated it was found that in daily life morality is handled in terms of personal characteristics instead of abstract moral principles. The paper suggests that the most appropriate approach to understanding everyday morality is to investigate these naturalistic conceptualizations.
\end{abstract}

\section{Anahtar kelimeler \\ Doğal kavramsallaştırmalar, sıradan insan, gündelik ahlak}

\section{Keywords}

Naturalistic conceptualizations, layperson, everyday morality

* $\quad$ İstanbul Üniversitesi, cesur@istanbul.edu.tr, ORCID: 0000-0002-4038-0592. 


\section{Giriș}

Ahlak, gündelik hayatımızın merkezinde olduğundan, üzerine belki de en fazla düşünülen insani meselelerden biridir. Başlangıcından beri felsefenin temel konusudur, günümüzde ise psikolojinin en sıcak konularından biri haline gelmiştir. Hal böyleyken geleneksel ahlak kuramlarından beri var olagelen bir problem olarak kuramsal ahlak ile gündelik ahlak arasındaki bağın zayıflığından bahsetmek belki de pek yanlış olmayacaktır. Bu yazıda, bu bağın zayıflığının muhtemel bazı sebepleri özetlenmeye çalışılacaktır.

Evrensel ahlak ilkeleri bulma arzusunun farklı kültürlerdeki ahlaki çeşitliliğinin anlaşılması önünde engel teşkil etmiş olması uzun zamandır tartısıılmaktadır. Ayrıca tümdengelimci ve tekçi yaklaşımlar da bu engeller arasında yer almıştır. Gerek geleneksel gerekse güncel kuramların araştırmalarında çoğunlukla hipotetik ikilemlerin ve bazen de sıradışı hipotetik ikilemlerin kullanılıyor olması ve dilin anlam dünyası taşıyıcıllğı etkisinin göz ardı ediliyor olması, ahlaki yargılamalarda önemli etkisi olan bağlamın yeterince incelenememiş olmasına yol açmıştır. Sıradan insanın gündelik yaşayışını oldukça etkileyen ahlakın kavramsallaştırılması da üzerinde durulması gereken önemli konulardandır.

Geleneksel ahlak kuramları ve bu kuramlara yönelik eleștiriler

\section{Batı temelli bir dünya görüșü}

Ahlak psikolojisi alanında çok uzun yıllar boyunca hakim olan Kohlberg'in bilişsel-gelişimsel ahlak kuramına göre, ahlakın en önemli bileşeni muhakemedir ve tek önemli ve evrensel olabilecek erdem de adalettir. Altı basamaklık ahlak modelini verilerden yola çıkarak oluşturduğundan kendi kuramını tümevarımcı olarak niteleyen Kohlberg (1968), aynı zamanda felsefi temelleri olmayan bir psikoloji kuramının eksik olacağını da ifade etmiştir. Zira Kohlberg'e göre (1971) iyi bir kuram, neden bir üst basamağa geçişin gerçekleşmesi gerektiğini ve bunun felsefi temellerini açıklamalıdır. Ancak kendi kuramının dayandığı felsefi temelleriyle, yani yalnızca Socrates, Kant ve Rawls gibi batılı filozofları temel almış olması dolayısıyla eleştirilere de maruz kalmıştır (Snarey, 1985). Öte yandan farklı kültürlerde yapılmış olan 45 çalışmayı inceleyen Snarey, Kohlberg'in ögelerinin çoğu kültürde bulunduğunu ama bazı kültürlerdeki yapıların Kohlberg'in sisteminde yer bulamadığını ifade etmiştir. Yine Snarey'nin aktardığına göre örneğin Gielen (1983) Kohlberg'in şemasının, Budist rahiplerin gelenek öncesi ve geleneksel muhakemeyi içerdiğini ama onların işbirliğini ve şiddet içermeyen ilkelerini içeremediğini ifade etmektedir. Gielen'ın çalışması, Kohlberg'in sisteminde yer almayan hayvanların hayatı, tanrılar, kast sistemine saygı ve saflık, kutsallık ve iffet konularına saygı konusunda da olgun ahlaki muhakemeler yapılabileceğini önermektedir. Snarey (1985), Kohlberg'in puanlama modeline göre kodlanamayan bu türden cevapların pek az raporlandığını veya analizinin pek az yapıldığını belirtmiştir, bu da kodlanamayan cevaplardaki problem alanlarının tam olarak 
tespit edilememesine yol açmı̧ gibi görünmektedir.

\section{Hipotetik ikilemlerin kullanılması}

Kohlberg'in sisteminde eleştirilen mesele, sadece basamakların evrenselliği meselesi değildir. Aynı zamanda hipotetik ikilemler kullanılmış olması da gündelik hayat ahlakının içeriğini kavramayı zorlaştırmaktadır. Hipotetik ikilemlerle yapılan pek çok çalışma; ikilemin türüne göre, gerçek hayat veya hipotetik bir ikilem olup olmadığına göre (Krebs, Denton, Vermeulen, Carpendale ve Bush, 1991; Smetana, Schlagman ve Adams, 1993) ve bazen aynı ikilemde bile farklı açılardan tartışılmasına bağlı olarak (de Vries ve Walker, 1986), ikilemle ilgili yargıların değişebildiğini göstermektedir. Her ne kadar Kohlberg (1968), yaklaşımını tümevarımcı bir yöntemle oluşturduğunu ifade etmiş olsa da Harman, Mason ve Sinnot-Armstrong'a (2010) göre, Kohlberg’in mülakat yaklaşımında ahlaki yargı için tümdengelimli bir yöntemi vardır. Ancak tümdengelim yöntemi konusunda eğitilmiş olanlar hariç Kohlberg'in katılımcıları, hiç bir zaman bu şekilde tümdengelimli cevaplar vermemişlerdir. Bu tümdengelim tarzı, daha ziyade kodlayıcılar ve cevapları yorumlayanlar tarafından eklenmiştir; Rest, Narvaez, Bebeau ve Thoma (1999) tarafından ifade edildiği şekliyle Kohlberg'in yaklaşımında “aradı̆̆ı filozofları bulacak şekilde sorular soruluyor”du. Ayrıca Kohlberg ve ekibi, katılımcılara açı bir şekilde nasıl muhakeme ettiklerini sormuşlardır. Bu tip sorulara çeşitli cevaplar vermiş olmalarına rağmen, bu durum katılımcıların bu yapay ortamların dışında, gündelik hayatın akışı içinde aynı argümanları kullanacakları anlamına gelmemektedir. Haidt (2001), örneğin Heinz’ın yaşadı̆̆ı ikileme dair cevaplarınızın her aşamada sorgulanmasının ("e ğer Heinz'ın karısı değil de komşusu olsaydı ilacı çalmalı mıydı?”) yoğun bir zihinsel çaba gerektirdiğini, ancak gündelik hayatta ahlaki kararların bu şekilde alınmayabildiğini ifade etmiştir. Dolayısıyla Haidt, Kohlbergvari ahlaki yargı mülakatlarını, sezgisel olarak verilen kararların sözelleştirilmesi istendiğinde gerçek yargılara ulaşılamayacağı iddiasıyla eleştirmiştir. Öte yandan yine Haidt, ahlaki şaşakalma kavramını incelerken (Haidt, Björklund ve Murphy, 2000) tam da benzeri bir mülakat yöntemi uygulamıştır.

\section{Tekçi ahlak eleştirisi}

Walker'a (2006) göre, ahlakın hem kişisel hem de kişiler arası bileşenleri vardır ve sosyal etkileşimleri, kişilerin haklarını ve refahıyla ilgili çatışmaları düzenleyen kişiler arası bileşen Kohlberg'in modelinde iyi temsil edilmiştir. Ancak Walker'a göre kişinin değerlerini, kimliğini, hedeflerini ve karakterini içeren kişisel bileşense Kohlberg'in modelinde göz ardı edilmiştir. Gilligan (1982, Gilligan ve Attanucci, 1988) ise Walker'ın kişiler arası bileşenin iyi işlenmiş olduğu görüşünün aksine, Kohlberg'in kişiler arası alanda adalet temelli ahlaki yönelimi vurgularken ilgi/bakım yönelimini göz ardı ettiğini ifade etmiştir. Gilligan'ın Kohlberg'in kuramının, kadınların farklı ahlaki yönelimlerini veya "farklı seslerini” içermediği eleştirisi, deneysel olarak ispatlanamamış olsa da (Jaffe ve Hyde, 2000; Thoma, 1986, Walker, 2006) bu eleştiri 
adalet temelli tekçi bir bir bakış açısını zorlamış ve kültür-ahlak ilişkisine de kapı açmış gibi görünmektedir. Görüldüğü üzere, ahlakın kişisel ve kişiler arası alanları ve muhtemel farklı yönelimleri sorgulanmaya başlanmıştır. Nitekim Graham ve arkadaşları (2011), ahlak eğer kültür, sınıf, politik görüş ve çağlara göre değişiyorsa psikologların ahlak alanını, örneğin sadece adalet, haklar ve iyilik gibi belirli kavramlarla temellendirmeyen bir tanımlama yapmaları gerektiğini iddia etmişlerdir. Ahlak sistemleri, gündelik hayatta insanlar birbirleriyle etkileştikçe, belirli yaşam problemleriyle karşılaştıkça ortaya çıkar ve tarihsel olarak şekillenmiş belirli kurumlarla, pratiklerle çeşitlenir veya sınırlandırılır. Bu da dünyanın farklı yerlerindeki gündelik yaşayışlara uygun, çok çeşitli gündelik ahlaki pratikleri mümkün kılmaktadır. Öte yandan Kohlberg (1986) de ahlak alanının çok geniş ve çeşitli olduğunu ve ahlakı kavramsallaştırma ve ölçme anlamında hiç bir yaklaşımın ahlaktaki bu çeşitliliği tüketemeyeceğini veya açıklamaya yetmeyeceğini belirterek farklı anlayışlara kapı aralıyor gibi görünmektedir.

\section{Güncel ahlak kuramlarına yönelik eleștiriler}

\section{Bağlamın göz ardı edilmesi}

Hipotetik ikilemlerin yetersizliğinden bahsederken tam da bu noktada ahlaki yargıları etkileyen en önemli faktörlerden biri olarak bağlamın önemine değinmek yerinde olacaktır. Gilligan'ın (1982), ahlakta hakim olan tekçi bakış açısını zorlayarak yeni bir ahlaki yönelimi gündeme getirmiş olmasının dışında, ahlak alanına önemli bir katkısı da hipotetik ikilemlerle değil, örneğin kürtaj kararı alıyor olmak gibi, katılımcıların gerçek hayat ikilemleriyle çalışmış olmasıdır. Ona göre bu gerçek hayat ikilemleri bağlam bakımından zengin, kişiyle ilişkili, ilişkisel özellikler taşıyan ve çerçeve bakımından ucu açık olan ikilemlerdir. Yine Cortese (1988) de Kohlberg'in ikilemlerinin gerçek hayattan kopuk olduğunu, çünkü hayatın içinde var olan çok boyutlu sonuçlar yerine kişileri ve /veya sonuçlarına hapsettiğini söylemektedir. Oysa ahlaki kararlarda bağlam en önemli çıkış noktalarından biri olabilmektedir.

Gerçek/gündelik hayat ahlakı vurgusunu yapan bir başka kuramcı da Bloom'dur (2011). Bloom’a göre, ahlak psikolojisinde bir kriz yaşamaktayız. Gerçek dünyadaki ahlaki yargılarımız çoğunlukla yakınlarımızla olan ilişkilerimize dairdir. Ancak alanda yapılan çalışmaların, ahlakı gündelik hayattan veya bağlamından kopardığı için yanlış tasarlanmış bilimsel çalışmalar olduğu ve dolayısıyla da bizi yanlış sonuçlara götürebildiğini iddia etmektedir. Ülkemizde ahlaki çatışmanın sıradan insan tarafından nasıl tanımlandığı, gündelik hayatta yaşanan olaylarda ahlakın nereye düştüğü, nelerin ahlak alanına girdiğini anlayabilmek amacıyla 490 kişi ile tanımlayıcı bir çalışma gerçekleştirmiştik (Cesur ve diğ., 2010). Katılımcılardan elde ettiğimiz ahlaki çatışma hikayelerini incelediğimizde, bunların genellikle gündelik hayatta ev, iş, aile veya arkadaş ortamında kişiler arası ilişkilerle ilgili olduğunu görmüştük. Verilen cevaplarda içinde yaşadığımız yakın coğrafyadaki savaşlar, çevre kirliliği, politik meseleler, 
ülkede yaşanan sorunlar vb. toplumsal olaylara neredeyse hiç rastlamamıştık. Rest, Narvaez, Bebeau ve Thoma'nın (1999) isimlendirdiği şekliyle makro ahlak, gündelik hayatta kendine yer bulmuyor ve ahlak mikro alan içinde düşünülüyor veya yaşanıyor gibi görünüyordu.

Bilişsel gelişim ile ahlaki gelişim arasındaki ilişkiyi incelediğim yüksek lisans tezimde (1997) Değerlerin Belirlenmesi Testi (Definig Issues Test-DIT) için bir pilot çalışma yapmıştım. Bu test, Kohlberg'in mülakatlarından elde edilmiş cevapların standart bir ölçek haline getirilmiş versiyonu sayılabilir (Cesur ve Topçu, 2010). Tezin gerçek verilerini toplamaya başlamadan önce yaptığım küçük bir pilot çalı̧̧mada katılımcılar, verilen standart cümleleri değerlendirmekte zorlanmış, pek çok soru sormuşlardı. Bunun üzerine ikinci bir pilot çalışma gerçekleştirmiş ve onları her hikayenin 12 standart cümlesi ile yönlendirmeden hikayeye dair kararları için kendi gerekçelerini almak istemiştim. On-67 yaşları arasında, 41 kadın ve 52 erkekten oluşan heterojen bir grubu oluşturan katılımcılar, hikayeleri okudular, sonrasında da verdikleri kararların gerekçelerini yazdılar. Cevapların içerik analizi, katılımcıların DBT’nde verilen meselelerden başka meseleleri de dikkate aldıklarını göstermişti. DBT'de yer alan basamaklara ait temalardan herhangi birine yerleştirilebilecek cevaplar A kategorisi, bunun dişındaki cevaplar da B kategorisi olarak kodlandı. Mann Whitney U Testi, Kategori B cevaplarının Kategori A cevaplarından anlamlı olarak daha fazla sayıda olduğunu göstermişti. Kategori B cevapları, alt kodlara ayrıldığında da 1) Testteki eylemlerden başka eylemlerin önerilmesi, 2) Durumun detayları hakkında daha fazla bilgi istenmesi, 3) Eylemin olası sonuçlarının düşünülmesi ve 4) Diğer başka meselelerdi. Bu test ile yaptığım pek çok çalışmada en çok sorulan sorulardan biri de Kohlberg'in Sefiller romanından esinle oluşturduğu Kaçak Mahkum hikayesindeki mahkumun, ihbar edilip edilmemesine karar vermeden önce, katılımcıların bu mahkumun hangi suçu işlediğini bilmek istemeleriydi. Katılımcılar olay hakkında karar verebilmek için hikayeye dair daha fazla bilgi sahibi olma ve bağlamı kurma ihtiyacı içindeydiler. Katılımcıların, hipotetik ikilemlerin dünyasına girememe sebeplerinden biri hipotetik düşünme kapasitesinin olmaması olabilir ancak eğitimlilerle daha az eğitimliler ve gençlerle yaşı daha büyük olanlar Kategori A ve Kategori B cevap tercihleri bakımından karşılaştırıldığında da sonuç değişmemişti. Her eğitim ve yaş grubundan katılımcı, özellikle bazı hikayelerde verili seçeneklerden birini tercih etme konusunda rahat olmamıştı. Shweder ve diğerleri (1987), bu noktada Kohlberg'in sisteminin sosyal bir sözleşmenin içine dahil olan soyut bireylerden oluşan bir toplum öngördüğünü ve bunun da esasında gerçeklikle bir bağlantısı olmadığını iddia etmektedirler. "Gerçek" ahlaki yargı, bağlamsaldır; yorum, anlama ve meseleleri düzenlemeyi gerektirir. Kurtiness de (1986) ahlaki tercihlerin hem bireysel farklılıkların hem de bağlamın sınırlılıklarının etkileşimiyle oluşan karmaşık kararlar olduğunu ifade etmektedir. Hipotetik durumlarla ilgili muhakemeler bize gerçek hayat durumlarındaki ahlaki yargılarla ilgili pek az şey anlatır. Çünkü gerçek hayat, ikilemlerdekinden daha karmaşık ve daha çok boyutludur. 


\section{Kültür, ilișkiler ve gündelik hayat}

Geleneksel ahlak kuramları, kültürel bağlamı da göz ardı etmiştir. Gündelik hayatın içine gömülü olan kültürü göz ardı etmek, ahlakın da eksik değerlendirilmesine sebep olabilmektedir. Bu anlamda psikolojiye, en önemli uyarı antropolojik ahlak kuramlarından gelmektedir. Shweder'e (2000) göre kültürel psikoloji zihnin (mind) değil, zihniyetlerin (mentalities) incelenmesidir, dolayısıyla bizimkinden farklı ahlak anlayışına sahip olanları görmemizi mümkün kılar. Shweder ve arkadaşları (1997), Hindistan'da yürüttükleri bir çalışma sonucunda, üç etik söyleme ulaşmışlardır. Özerklik Etiği'nde (Ethics of Autonomy) zarar, haklar ve adalet kavramları önemli yer tutar. Topluluk Etiği (Ethics of Community) görev, hiyerarşi, karşıllklı bağımlılık gibi kavramların yer aldığı bu etik anlayışı, topluluğu oluşturan rollerin ve bütünün ögeleri arasındaki ilişkinin önemiyle ilgilidir. Kutsallk Etiği (Ethics of Divinity); kutsal düzen, doğanın düzeni, gelenek, kutsallık, günah ve kirlilik gibi kavramlara dayanır. Sıradan insanların ahlakı nasıl kavramsallaştırdığını görmek istediğimiz bir çalışmada (Cesur ve diğ., 2020), açık uçlu olarak "ahlak, ahlaksızlık, ahlaklı insan...." gibi kavramların tanımlanmasını istedik. Tümdengelimsel bir analiz yürütmemiş olmamıza rağmen elde ettiğimiz kategorilerin kümeleme analizleri, Shweder'in üç etik koduna benzer bir yapı ortaya koymaktaydı. Bu bulgular, farklı yaklaşımlarla ve farklı kültürlerden elde edilen verilerin birbirini desteklemesine iyi bir örnek oluşturmaktadır. Bu noktada hangi gündelik kültürel ögeler veya hangi gündelik hayat pratiklerinin bu benzerliği sağladığı üzerine düşünülebilir ve çeşitli yöntemlerle bunun nedenleri araştırılabilir.

Ahlak alanına bir diğer önemli katkı da yine başka bir antropolog olan Alan Fiske'ten gelmiştir. Fiske (1992), batı psikolojisinin insanları genel olarak asosyal bireyciler olarak gördüğünü iddia etmektedir ve ona göre psikoloji genellikle birey içi bilişsel ve duygusal işlevleri inceler. Day ve Tappan'ın (1996) da iddia ettiği gibi geleneksel ahlak çalışmaları, ahlakı bağlamından uzaklaştırmıştır, oysaki benlik bilişsel-gelişimcilerin önerdiğinden daha fazla sosyal bir fenomendir. Nitekim Fiske (1992) geleneksel yaklaşıma alternatif bir paradigma önermektedir; insanlar temel olarak sosyaldirler, sosyal hayatlarını öteki insanlarla ilişkileri üzerinden düzenlerler. Rai ve Fiske (2011) sosyal ilişkisel bağlamları göz ardı ederek davranışın zarara sebep olup olmadığı, adaletli olup olmadığı veya saflığı bozup bozmadığı gibi sadece sonuçlara göre ahlaki yargıların temellendiği varsayımını bırakmamamız gerektiğini iddia etmektedirler. Fiske'in (1992) yaklaşımına göre ahlak, ilişkileri düzenleyen sosyal bir mekanizmadır ve bu mekanizma dört farklı ilişkisel motivasyon ile işlemekte ve dolayısıyla dört farklı ilişki modeli oluşturmaktadır: Herkesin birlik içinde ve birbirini gözeterek yaşadığı müşterek paylaşım (communal sharing), hiyerarşik ilişkilerin ön planda olduğu otorite düzeni (authority ranking), eşit dağılım ve karşılıklılı̆̆ın ön planda olduğu eşit ilişki (equality matching) ve oransal dağılıma bağlı düzenlenen orana dayalı ilişki düzeni (market paricing). Sosyal hayatın düzenlenmesinde sadece ilişki tipleri değil ilişkilerin bir birleşimi olan ve çeşitli ilişkilerin koordine edildiği metailişkisel modeller (metarelational models) de devreye girebilmektedir (Fiske, 2012). 
Fiske'e göre, bireysel psikolojiyi, ikili sosyal ilişkileri veya grup psikolojisini, sosyal ilişkilerin koordinasyonlarını anlamadan anlayamayız. İki sevgili arasındaki ilişki, hiçbir zaman sadece iki sevgili arasındaki ilişki olarak kalmaz. Örneğin iki kişi evlendiğinde aileler de evlenir. Dolayısıyla herhangi bir davranışın ihlal olup olmadığı, yanlış olup olmadığı ilişki içinde ve hatta metailişkiler ağı içinde anlam kazanmaktadır. Dolayısıyla ilişkilerle yoğrulu bu gündelik hayattan kopartılmış ve kendi zihni içine hapsedilmiş bireyi incelemek, ahlaka dair anlayışımızı eksik bırakmaktadır. Esasında herkes ahlakın içkin olarak sosyal olduğu noktasında hemfikir olabilir, ancak yapılan çalışmaların çoğunda Fiske'in İlişki Modelleri Kuramı'nın önerdiği şekliyle ahlakın ilişkiler bağlamında ele alınmaması, belki de sosyal psikolojinin, esasında da hayatın sosyal kısmını eksik bırakmaktadır (Sunar ve diğ., 2021).

Graham ve diğerleri (2013), Kohlberg'in ve yakın çalışma arkadaşlarının ahlakı tekçi bir bakış açısıyla ele almalarından, yani ahlakı özellikle örneğin adalet olarak tanımlamalarından sonra gittikçe artan oranlarda çoklu bir anlayışa doğru geçildiğini ifade etmektedirler. Bu çoğulculukta özellikle de yukarıda da anlatılan kuramlarıyla, Shweder ve Fiske gibi antropologların rolü büyüktür.

\section{Sıradıșı hipotetik ikilemlerin kullanılması}

Günümüze doğru yaklaştıkça Kohlberg, ahlak alanındaki hakimiyetini kaybetmiş, onun kuramının üstünden pek çok kuram geçmiş ve ahlaka olan tekçi yaklaşım artık yerini çoğulcu bir yaklaşıma bırakmış olsa da hipotetik ikilemler varlığını halen sürdürmektedir. Graham (2014), ahlak biliminde son yıllarda büyük bir atılım gerçekleşmiş olmasına rağmen araştırmaların, başıboş vagonlar (runaway trolleys), ensest ilişki, bayrakla temizlik yapmak veya ölü bir tavukla cinsel ilişki gibi varsayımsal, yapay ve gündelik hayatta neredeyse hiç örneği olmayan sıradışı ikilemlerle meşgul olduğunu ifade etmektedir.

Günümüzün en popüler ahlak kuramlarından olan Ahlaki Temeller Kuramı'nda (Graham ve diğ., 2013) da Shweder, Fiske, Shwarzt'ın değerler yaklaşımı ve evrimsel bazı yaklaşımları temel alarak oluşturulmuş beş ahlaki temelden bahsedilmektedir: bakım/zarar (care/ harm), adalet/hilekarlık (fairness/cheating), sadakat/ihanet (loyalty/betrayal), otorite/yıkım (authority/subversion) ve kutsallık/bozulma (sanctity/degradation). Ancak bu kuram çerçevesinde yapılan pek çok araştırmada gerçek hayattan uzak ve sıradışı ahlaki ikilemler kullanılmaktadır. Turiel'e göre (2008) ise bazı kültürlerde insanlar köpek eti yemek gibi meselelere çok otomatik bir şekilde benzer tepkiler veriyorlar diye (Haidt, Koller ve Dias, 1993) bütün ahlaki süreçlerin böyle işlediği ve varsayımı ve bir iki örnek hikaye üzerinden insanların geri kalan durumlar için de benzer şekillerde karar verip vermediği test edilmemiştir. Benzer şekilde Gray ve Keeney (2015) de Ahlaki Temeller Kuramı'nın kullandığı bozulma senaryolarının idrar içme veya köpek yemek gibi oldukça sıradışı ve sert içeriklere sahip olduğunu, bu sıradışı ve sert içeriklerinin de esasında olmayan ahlaki temel farklılıkları ortaya çıkardığını iddia etmişlerdir. Kendi çalışmalarında daha ılımlı içeriklere sahip gerçek hayat senaryoları 
kullandıklarında saflık ve zarar alanlarının birbirinden ayrılmadığını bulduklarını ifade etmişlerdir. Chakroff, Dungan ve Young (2013) yaptıkları deneylerde zarar ve saflık (purity) içeren eylemlerin hedeflerini kendi yönelimli ve başkası yönelimli olarak değişimlemişlerdir. Neticede eylem eğer başkası yönelimliyse, yani ihlal eyleminin hedefi bir başkasıysa bu eylem zarar olarak, eğer hedef kişinin kendisiyse de bozulmuşluk (impure) olarak algılanmıştır. Dolayısıyla Ahlaki Temeller Kuramı'nın öngördüğünün dışında, ahlaki kararı belirleyen şey sadece eylemin kendisi değil, aynı zamanda bu eylemin kime yöneltildiğidir. Aşağıda biraz daha detaylarıyla ele alacağım "Bana göre ahlak" çalışmasında (Cesur ve diğ., 2020) ise tanımlanan kişinin kim olduğuna göre (örneğin ahlaksız kadın veya ahlaksız erkek) ahlak kavramsallaştırmalarının farklılaşabileceğini gördük. Bu sonuçlar bizi yine ahlaki kararların bağlamdan kopuk verilmediğini, davranışın kime yönelik olarak yapıldığının veya kimin davranışı olarak tanımlandığının, davranışların nasıl değerlendirildiğini etkilediğini göstermektedir. Dolayısıyla Ahlaki Temeller çerçevesinde gerçek hayattan uzak sıradışı ikilemler kullanılıyor olması ve bu ikilemler içinde sadece belirli davranışların zararlı veya saflığı bozan davranışlar olarak ele alınıyor olması, davranışın gerçekleştiği bağlamın veya kişiler arası ilişkilerin göz ardı ediliyor olmasını da beraberinde getirmektedir.

Gündelik hayatın içinde ahlakın taşıyıcısı olan dilin göz ardı ediliyor olması

Kültür söz konusu olduğunda dikkate alınması gereken en önemli faktörlerden biri de o kültürün taşıyıcısı olan dildir. Heubner ve Garrod (1993) ergen ve genç-yetişkin Tibetli rahiplerle yürüttükleri çalışmada Budist felsefesinin temelini oluşturan "karma” inancının çok merkezi bir öneme sahip olması dolayısıyla rahiplerin ahlaki muhakemelerini Kohlberg'in şemasına göre kodlanmanın zor olduğunu gördüklerini ifade etmişlerdir. Dolayısıyla da sosyo-kültürel duyarlılığın, ahlak araştırmalarında çok önemli bir yere sahip olması gerektiğini ifade eden Heubner ve Garrod, bir kültürün ahlak alanını inceleyebilmek için o kültürün tarihini, felsefesini ve dilini öncelikle anlamak gerektiğini iddia etmişlerdir. Kelime karşılı̆̆ı ile anlaşılamayacak olan "karma” gibi kavramları anlamak gerektiğini, bu tür kavramlar için kelime karşılığını vermenin yeterli olmayacağını iddia etmişlerdir. Karma inancına göre niyetli olarak yapılmış ahlaki olmayan bir davranış, dikkatsiz bir eylem veya bilgisiz ve yanlış yönlendirilmiş bir eylem acıya sebep olabilir ve bunun düzeltilmesi gerekir (Shweder ve arkadaşları, 1997). Nitekim Fiske (2020) de benzer bir vurguyla her dilde kelimelerin veya kavramların düz veya çağrışımsal anlamlarından gelen belirsizliklerin, kültürler arası araştırmaların temel sıkıntılarından biri olduğunu ifade etmektedir. Namus kavramının da katılımcıların anlatılarında sıkça yer aldığı bir çalışmamızı (Koç ve Cesur, 1999) İngilizce’ye çevirmekte zorlanmış, kavramı detaylı bir şekilde anlatmak durumunda kalmıştık, kelimenin birebir çevirisi anlamı vermekte yetersiz kalmaktaydı. Hatta bu çalışmamıza Hollandalı bir akademisyen tarafından getirilen yorum, duruma güzel bir örnek de oluşturuyor: "Sizin namus cinayeti dediğiniz şeye bir kıskançlık cinayeti diyoruz.” Doğrusu namus cinayeti ile kıskançlık cinayetinin aynı şey 
olmadığını anlatmakta da zorlanmıştım. Dolayısıyla ahlak çalışmalarının, insanların anlam dünyalarını hesaba katmadan yapılması pek mümkün görünmemektedir. Vygotsky’ye göre (1934/1985) ahlaki gelişim, sosyal ilişkilerin semiotik ve dilsel içselleştirilmesiyle gerçekleşir, insanlar arası dışsal konuşmalar kişi içi konuşmalar haline gelir ve dışsal-açık diyaloglar sessiz-içsel diyaloglar halini alır. Böylelikle içinde yaşanılan kültür, dil vasıtasıyla bireylerin anlam dünyasını oluşturur. Dolayısıyla Tappan (1997) örneğin Budist geleneğindeki "karma"nın (veya Türkiye'de örneğin namusun) sadece belirli bir ahlaki veya dini anlam içeren bir sembol olmadığını, aynı kültürü paylaşan kişilerce düşünme, hissetme ve eyleme açısından gündelik bir ahlaki dilin parçası olduğunu belirtmektedir.

Öte yandan gündelik hayatımızı yaşayışımız, anlatısal (narrative) bir formda gerçekleşmektedir (Gergen ve Gergen,1986; Paker ve Cesur, Temmuz 2011). Hayatımızı; geçmişimiz, şimdimiz ve gelececeğimizi hikayeleştirerek yaşarız. Benliğimiz ve kimliğimiz de bu hikayesel anlatılarda gömülüdür. Shweder (akt. Snarey, kişisel konuşma, Şubat 1984) Hindistan toplumunun ahlaki geleneksel söyleminin anlatısal olduğunu ifade etmektedir. Katılımcılar, Kohlberg'in açık uçlu mülakat sorularına "Dur ben sana bir hikaye anlatayım" diye cevap verdiklerinde ve dinleyenin bundan bir ders çıkarmasını bekledikleri bir ahlaki bir ders anlattıklarında, oldukça iyi eğitilmiş Kohlberg mülakatçıları bile bu malzemeyi kodlamakta zorlanmışlardır. Bunun sebeplerinden biri, katılımcının cevap veren kişi rolünden çıkıp mülakatçının muhakemesini uyararak öğretmen rolüne geçmesidir. Bir yandan da bunun diğer bir sebebi, hikayelerle örülü ahlaki ilkeler dünyasının Kohlberg'in sistemiyle örtüşmemesidir. Nitekim Kohlberg de Snarey'e (akt. Snarey, kişisel konuşma, Şubat 1984) bu tür malzemenin kişisel olarak çalıştığı diğer kültürler arası mülakatlar kadar kolaylıkla puanlanamadığını ifade etmiştir. Gündelik hayatın hikayelerle örülü yapısı, olayların "hakikat"ini (veya oldukları halini) göstermez, daha ziyade süregiden olayların söylemine dair ve ortak kültürel formlara dair birşey gösterir (Tappan, 1989). Ahlaki hikayelerle örülü kişisel anlatıları yakalayabilmek için (Tappan, 1999) ahlak alanyazınında pek az yer tutan otobiyografik çalışmalara daha fazla ağırlık verilmesi gerektiği aşikardır.

\section{Ahlakın doğal kavramsallaștırmaları}

Anlatısal veya otobiyografik çalışmalar daha ziyade kişilerin kendi hayat olaylarını ve yaşantılarını ahlak çerçevesinde nasıl kurguladıklarının ipuçlarını vermektedir. Öte yandan kendi hayat kurgumuz kadar, ahlakın ne olduğuna veya ahlaklı kişilerin nasıl insanlar olduğuna dair kurgularımız da gündelik hayatımızın önemli bir parçasını oluşturmaktadır. Ancak bugünkü ahlak araştırmalarında sıradan insanın doğal ahlak kavramsallaştırmalarının pek fazla çalışılmamış olduğunu görmekteyiz (Walker ve Pitts, 1998). Sıradan insanların ahlakı nasıl ele aldığını anlamak, bu kavramsallaştırmaların gündelik yaşayışı etkiliyor olması dolayısıyla oldukça önemlidir (Hardy, Walker, Olsen, Skalski ve Basinger, 2011; Hoffman, Wisneski, Brandt ve Skitka, 2014). Bu yöntemle ilk çalışan kişiler olan Shaffer (1994) Quin, Houts ve 
Graeser (1994), insanlara ahlakın onlar için ne anlama geldiğini, açık uçlu olarak sormuşlar ve cevapları herhangi bir kurama dayandırmaksızın analiz etmişlerdir. Her iki araştırmanın bulguları da geleneksel ahlak kuramları içinde en fazla yer tutan eşitlik, adalet veya merhamet gibi ilkeler yerine ahlakın daha ziyade kişi atıfları veya belirli bazı erdemlerle inşa edildiğini göstermiştir.

Biz de sıradan insanın ahlakın nasıl kavramsallaştırıldı̆̆ını ve aynı zamanda bu kavramsallaştırmalarda genel bazı tanımların mı yapıldığ 1 yoksa tanımlanan hedefe göre farklılaşmalara mı rastlandığını incelemek istedik (Cesur ve diğ., 2020). İstanbul'da ikamet eden ve üniversite öğrencisi (\%58.06) ve yetişkin (\%41.94) toplam 251 katılımcıya açık uçlu sorular yönelttik. Katılımcılardan, "Bana göre ahlak, ahlaklı insan, ahlaklı kadın, ahlaklı erkek, ahlaksızlık, ahlaksız insan, ahlaksız kadın ve ahlaksız erkek” şeklindeki 8 ayrı cümleyi tamamlayarak bu hedef kişi veya kavramları tanımlamalarını istedik. Önceki çalışmalarla (Cesur, 2003; 2006) da paralel bir şekilde yukarıda bahsedilen bu sekiz kavramın da tanımında en çok karşımıza çıkan cevap, toplumsal kurallara uymak olmuştur. Tekrar tekrar karşımıza çıkıyor olması dolayısıyla toplumsal kurallar ve toplumsal düzen, ahlakı anlayışımızda oldukça önemli bir yere sahip gibi görünmektedir. Ahlak ve ahlaksızlık tanımlamalarında genel ilkelerden bahsediliyorken, Tıpkı Walker ve Pitts (1998), Hardy ve diğerleri (2011) ve Smith, Smith ve Christopher'ın (2007) çalışmalarında olduğu gibi ahlaklı insan, ahlaksız insan gibi kişiler tanımlanırken ahlak kuramlarında pek yer almayan kişisel özellikler, özellikle de dürüstlük, erdem ve vicdanlı olmak gibi bireysel özellikler sıklıkla verilen cevaplardandır. Nitekim Blasi (1980) de, ahlaki muhakemenin çok da iyi anlaşılamamış olmasının sebebini kişisel standartlar üzerinden karar veren insanların, ahlaki muhakemelerinin rasyonel açıklamalarına odaklanmak olduğunu ifade etmiştir.

Ahlak kuramlarında kendine pek de yer bulamayan bir özellik olarak dürüstlük, bizim çalışmamızda ahlaklı ve ahlaksız insanın tanımlanmasında sıklıkla karşımıza çıkmıştır. Herhangi bir kurama dayanmayan ve katılımcıların kendiliğinden ürettikleri cevaplarda en sıklıkla dürüstlük özelliğinin yer alması, kuramların bu özelliği genellikle pas geçmiş olmasına rağmen bu özelliğin sıradan insanın hayatındaki önemine işaret etmektedir (Cesur, 2003, 2006; Cesur ve diğ., 2018; Cesur ve diğ. 2021; Hardy ve diğ. 2011; Karasu ve diğg., 2021; Reimer, DeWitt Godelock ve Walker, 2009).

Ahlaklı kadın ve ahlaklı erkek tanımlamaları, sadece namus atfı dolayısıyla farklılaşmaktayken ahlaksız kadın ve erkek tanımlamaları birbirinden oldukça farklıdır. Ahlaksız kadın tanımlarında, saygı görmek, namus, terbiye ve sosyal roller gibi daha toplumsal tanımlamalar yapılırken ve ahlaksız kadının toplumdaki olumsuz yerine atıfta bulunulurken ahlaksız erkekler için bireysel özellikler olarak erdemli olmak ve dürüstlük kategorilerinden cevaplar gelmiştir. Bu bulgular, gündelik hayatta ahlakın toplumsal cinsiyet rolleri ile örülü bir şekilde ele alındığını ve karşımızda kim olduğuna bağlı olarak farklı ahlaki atıflar yapabileceğimizi göstermektedir. 


\section{Sonuç}

Psikoloji araştırmalarının çoğu batılı, bireyselci, eğitimli vs. örneklemlerle yürütülmüştür ve yürütülmektedir ("WEIRD-White, Educated, Industrialized, Rich, and Democratic" samples, Henrich, Heine ve Norenzayan, 2010). Oysaki gündelik hayatı veya sıradan insanın ahlakını anlamak istiyorsak gerçekten de bunu sıradan insana sormakta fayda vardır. Katılımcılarımızın sıradışı hikayelerle şaşakalmalarına yol açmak veya birtakım standart ölçek cümleleriyle onları ölçüp biçtiğimizi varsaymak yerine gündelik hayatın ahlakının, insanın sosyalliğinin, bağlamın, kültürün, dilin veya ahlakın doğal kavramsallaştırmalarının derinlemesine çalışılmasına da odaklanılmasında fayda vardır. Sonuç olarak çeşitli ahlak kuramlarının güvenli alanlarından çıkıp sıradan insanın hikayesini onun "kendi sesi"nden dinlemenin önemini kavramak gerekmektedir.

\section{Kaynakça}

Blasi, A. (1980). Bridging moral cognition and moral action: A critical review of the literature. Psychological Bulletin, 8, 1-45.

Bloom, P. (2011). Family, community, trolley problems, and the crisis in moral psychology. The Yale Review, 99, 26-43.

Cesur, S. (1997). The relationship between cognitive and moral development. [Yayınlanmamış yüksek lisans tezi], Boğaziçi Üniversitesi.

Cesur, S. (2003). Morality conceptions within a group of Turkish adults [Poster sunumu] 29th Annual Conference Association for Moral Education, Jagiellonian University, Krakow, Polonya.

Cesur, S. (2006). Toplumumuzda ahlakın kavramsallaştırılması. Y. Mehmedoğlu, A.U. Mehmedoğlu (Ed.), Küreselleşme, ablak ve değerler içinde (321-349). Litera Yayınları.

Cesur, S., Bayad, A., Yılmaz, O. ve Tepe, B. (2018). Bir değerler skalasının geliştirilmesi ve bu skalanın politik ve dini yönelimle ilişkisi. Elektronik Sosyal Bilimler Dergisi, 17(66), 401-420.

Cesur, S. ve Topçu, M.S. (2010). Değerlerin Belirlenmesi Testinin güvenirlik ve geçerlik çalışması ve yaş, eğitim, cinsiyet ve ebeveyn eğitiminin ahlak gelişimi ile ilişkisi. Kuram ve Uygulamada Eğitim Bilimleri, 10(3), 1657-1696.

Cesur, S., Tepe, B., Piyale, Z.E., Sunar, D. ve Biten, F.A. (2020). "Bana göre” ahlak: Sıradan insanın ahlakı kavramsallaştırması. Türk Psikoloji Yazıları, 23(45), 115-138.

Cesur, S., Kahraman, F., Turgut, İ., Deveci, E., Altınal, B. E., Aygül, Z. ve Yetkinoğlu, Ö.(2010). Yaşanan ahlaki çatışma örnekleri üzerinden Türkiye'de gündelik ahlak anlayışı. Elektronik Sosyal Bilimler Dergisi (www.e-sosder.com), 9(32), 348-367.

Chakroff, A., Dungan, J. ve Young, L. (2013). Harming ourselves and defiling others: What determines a moral domain? PLOS ONE, 8(9), 1-12. 
Cortese, A. J. (1988). The interpersonal approach to morality: A gender and cultural analysis. The Journal of Social Psychology, 129(4), 429-441.

Day, J. M. ve Tappan, M. B. (1996). The narrative approach to moral development: From the epistemic subject to dialogical selves. Human Development, 39(2), 67-82. https://doi.org/10.1159/000278410

deVries, B. ve Walker, L. (1986). Moral reasoning and attitudes toward capital punishment. Developmental Psychology, 22, 509-513.

Fiske, A. P. (1992). The four elementary forms of sociality: Framework for a unified theory of social relations. Psychological Review, 99, 689-723. http://dx.doi.org/10.1037/0033-295X.99.4.689

Fiske, A. P. (2012). Metarelational models: Configurations and social relationships. European Journal of Social Psychology, 42, 2-18.

Fiske, A. P. (2020). The lexical fallacy in emotion research: Mistaking vernacular words for psychological entities. Psychological Review, 127, 95-113. http://dx.doi.org/10.1037/rev0000174

Gergen, K. ve Gergen, M. (1986). Narrative form and the construction of psychological science. T. Sarbin (Ed.) Narrative psychology. The storied nature of human conduct içinde. Praeger.

Gilligan, C. (1982). In a different voice: Psychological theory and women's development. Harvard University Press.

Gilligan, C. ve Attanucci, J. (1988). Two moral orientations: Gender differences and similarities. Merrill-Palmer Quarterly, 34, 223-237.

Graham, J. (2014). Morality beyond the lab. Science, 345, 1242

Graham, J., Haidt, J., Kolevaa, S., Motylc, M., Iyer, R., Wojcikd, S.P. ve Ditto, P.H. (2013). Moral Foundations Theory: The pragmatic validity of moral pluralism. Advances in Experimental Social Psychology, 47, 55-130.

Graham, J., Nosek, B. A., Haidt, J., Iyer, R. Koleva, S. ve Ditto, P. H. (2011). Mapping the moral domain. Journal of Personality and Social Psychology, 101(2), 366-385.

Gray, K. ve Keeney, J.E. (2015). Impure or just weird? Scenario sampling bias raises questions about the foundations of morality. Social Psychological and Personality Science, 6(8), 859-868.

Haidt, J. (2001). The emotional dog and its rational tail: A social intuitionist approach to moral judgment. Psychological Review, 108, 814-834.

Haidt, J., Björklund, F. ve Murphy, S. (2000). Moral dumbfounding: When intuition finds no reason. Unpublished manuscript, University of Virginia.

Haidt, J., Köller, S.H. ve Dias, M.G. (1993). Affect, culture, and morality, or is it wrong to eat your dog? Journal of Personality and Social Psychology, 65, 613-628.

Hardy, S. A., Walker, L. J., Olsen, J. A., Skalski, J. E., \& Basinger, J. C. (2011). Adolescent naturalistic conceptions of moral maturity. Social Development, 20(3), 562-586. doi:10.1111/j.1467-9507.2010.00590.x

Harman, G., Mason, K. ve Sinnot-Armstrong, W. (2010). Moral reasoning. J.M. Doris (Ed.) The moral psychology handbook içinde (s.206-245). Oxford University Press.

Henrich, J., Heine, S. J. ve Norenzayan, A. (2010). The weirdest people in the world? Behavioral and Brain Sciences, 33, 61-83. http://dx.doi.org/10.1017/S0140525X0999152X 
Heubner, A. M. ve Garrod, A. C. (1993). Moral reasoning among Tibetian monks: A study of Buddhist adolescents and young adults in Nepal. Journal of Cross-Cultural Psychology, 24(2), 167-185.

Hofmann, W., Wisneski, D. C., Brandt, M. J. ve Skitka, L. J. (2014). Morality in everyday life. Science, 345(6202), 1340-1343.

Jaffe, S. ve Hyde, J.S. (2000). Gender differences in moral orientation: A meta-analysis. Psychological Bulletin, 126, 703-726.

Karasu, M., Aykaç, B., Çelikadam, C., Balım, S., Aktaş, B. ve Cesur, S. (2021). Okul çağındaki çocukların ahlaka ilişkin gündelik kavramsallaştırmaları: Keşifsel bir inceleme. Nesne, 9(21), 535-554. DOI: 10.7816/ nesne-09-21-04

Koç, A. A. ve Cesur, S. (1999). Moral-conventional evaluations: subcultural differences. [Poster sunumu] European Psychology Congress, Rome, Italy.

Kohlberg, L. (1968). The child as a moral philosopher. Psychology Today, 2, 25-30.

Kohlberg, L. (1971). From is to ought: How to commit the naturalistic fallacy and get away with it in the study of moral development. T. Mischel (Ed.), Cognitive development and epistemology içinde (s. 151-284). Academic Press.

Kohlberg, L. (1981). The philosophy of moral development: Moral stages and the idea of justice. Harper and Row.

Kohlberg, L. (1986). A current statement on some theoretical issues. S.Mogdil ve C. Mogdil (Eds.) Lawrence Kohlberg: Consensus and controversy (s. 484-546) içinde. The Palmer Press.

Krebs, D., Denton, K. L., Vermeulen, S. C., Carpendale, J. ve Bush, A. (1991). Structural flexibility of moral judgment. Journal of Personality and Social Psychology, 61, 1012-1023.

Kurtiness, W. M. (1986). Moral behavior as rule governed behavior: Person and situation effects on moral decision making. Journal of Personality and Social Psychology, 50(4), 784-791.

Paker, O.K. ve Cesur, S. (Temmuz 2011). Self construction throughout a narration of loss:Self positioning and self-examination of people who experienced the death of a first degree close relative. [Poster sunumu] The 12th European Congress, İstanbul.

Quinn, R.A., Houts, A.C. ve Graeser, C.A. (1994). Naturalistic conceptions of morality: A question-answering approach. Journal of Personality, 62, 239-262.

Rai, T. S., ve Fiske, A. P. (2011). Moral psychology is relationship regulation: Moral motives for unity, hierarchy, equality, and proportionality. Psychological Review, 118, 57-75. http://dx.doi.org/10.1037/a0021867

Reimer, K. S., DeWitt Goudelock, B. M. ve Walker, L. J. (2009). Developing conceptions of moral maturity: Traits and identity in adolescent personality.The Journal of Positive Psychology,4(5),372-388. doi:10.1080/17439760902992431

Rest, J., Narvaez, D., Bebeau, M. ve Thoma, S. (1999). A Neo-Kohlbergian approach: The DIT and Schema Theory. Educational Psychology Review, 11(4), 291-324.

Shaffer, D.R. (1994). Do "naturalistic" conceptions of morality provide any novel answers? Journal of Personality, 62(2), 263-268.

Shweder, R.A. (2000). The psychology of practice and the practice of three psychologies. Asian Journal of Social Psychology, 3, 207-222. 
Shweder, R.A., Mahapatra, M. ve Miller, J.G. (1987). Culture and moral development. J. Kagan ve S. Lamb (Eds.) The emergence of morality in young children içinde (s. 130-204). University of Chicago Press.

Shweder, R. A., Much, N. C., Mahapatra, M. ve Park, L. (1997). The 'big three' of morality (autonomy, community, divinity) and the 'big three' explanations of suffering. A. M. Brandt ve P. Rozin (Eds.), Morality and health içinde (s. 119-169). Routledge.

Smetana, J. G., Schlagman, N. ve Adams, P. W. (1993). Preschool children's judgments about hypothetical and actual transgressions. Child Development, 64, 202-214.

Smith, K. D., Smith, S. T. ve Christopher, J. C. (2007). What defines the good person? Cross-cultural comparisons of experts' models with lay prototypes. Journal of Cross-Cultural Psychology, 38(3), 333-360.

Snarey, J. (1985). Cross-cultural universality of social-moral development: A critical review of Kohlbergian research. Psychological Bulletin, 97, 202-232.

Sunar, D., Cesur, S., Piyale, Z. E., Tepe, B., Biten, A. F., Hill, C. T. ve Koç, Y. (2021). People respond with different moral emotions to violations in different relational models: A cross-cultural comparison. Emotion, 21(4), 693-706. https://doi.org/10.1037/emo0000736

Tappan, M. B. (1989). Stories lived and stories told: The narrative structure of late adolescent moral development. Human Development, 32, 300-315.

Tappan, M. B. (1997). Language, culture, and moral development: A Vygotskian perspective. Developmental Review, 17, 78-100.

Tappan, M. B. (1999). Authoring a moral self: A dialogical perspective. Journal of Constructivistic Psychology, $12,117-131$.

Thoma, S. J. (1986). Estimating gender differences in the comprehension and preference of moral issues. Developmental Review, 6, 165-180.

Turiel, E. (2008). The development of children's orientations toward moral, social, and personalorders: More than a sequence in development. Human Development, 51, 21-39.

Vygostky, L. S. (1934/1985). Düşünce ve dil (çev.S. Koray). Kaynak Yayınları.

Walker, L. J. (2006). Gender and morality. M. Killen ve J. Smetana (Eds.), Handbook of moral development içinde (s. 93-115). Lawrence Erlbaum Associates, Publishers.

Walker, L. J. ve Pitts, R. P. (1998). Naturalistic conceptions of moral maturity. Developmental Psychology, 34(3), 403-419. 